Tatiana $V$. Derguilyova, Ph. D. in Pedagogics

State Public Scientific and Technical Library of the Siberian Branch of the Russian Academy of Sciences (Novosibirsk, Russia) dergileva@spsl.nsc.ru

Natalia I. Podkorytova, Ph. D. in Pedagogics State Public Scientific and Technical Library of the Siberian Branch of the Russian Academy of Sciences (Novosibirsk, Russia) podkorytova@gpntbsib.ru

\title{
INFLUENCE OF LIBRARY ENVIRONMENT ON INFORMATION SPACE OF NOVOSIBIRSK SCIENTIFIC CENTRE OF SIBERIAN BRANCH OF THE RUSSIAN ACADEMY OF SCIENCES
}

\begin{abstract}
The paper discloses timeline of research and educational infrastructure of Novosibirsk Research Center of the Siberian Branch of the Russian Academy of Sciences (Novosibirsk, Russia). Some results of comparative analysis of quantitative indicators describe a level of popularity of library and information resources stocked in Novosibirsk Research Center, State Public Scientific and Technical Library of the Siberian Branch of the Russian Academy of Sciences, Novosibirsk State University are given. Types of named libraries' readers' information motivation are briefly described. Authors of the article outline their own view on specifics of influence that library environment has on quality of information support of research and educational activities of scholars and students from Novosibirsk Research Center of the Siberian Branch of the Russian Academy of Sciences.

Key words: Novosibirsk Research Center, State Public Scientific and Technical Library of the Siberian Branch of the Russian Academy of Sciences, information support for research activities, research activities, educational activity, library sources for research work, integration of scientific information resources.
\end{abstract}

УДК 004.738.1Национальная электронная библиотека:021(470+571)

DOI: $10.32340 / 2414-9101-2020-3-67-73$

А. А. Фомина, кандидат педагогических наук, доцент Алтайский государственный институт культуры (Барнаул, Россия) terrarium46@gmail.com

\section{ЦИФРА И ТЕКСТ}

Аннотация. По инициативе крупнейших библиотек современной России в 2004 г. была создана Национальная электронная библиотека, предоставляющая читателям свободный доступ к коллекциям оцифрованных документов и каталогам изданий, находящихся на хранении в отечественных библиотеках. Степень полноты этого общедоступного информационного продукта, включающего к настоящему моменту более 40,5 млн библиографических записей и около 5 млн электронных документов, положительно характеризует перспективы создания российского общенационального информационного пространства, идейные истоки которого восходят к концепции единого общесоюзного библиотечного фонда, ставшей синтезом научных взглядов отечественных фондоведов XIX-XX вв. Весомый вклад в становление этой концепции принадлежит известным отечественным библиотековедам Ю. Н. Столярову и Ю. А. Гриханову.

Ключевые слова: Национальная электронная библиотека, доступность информации, информация, информационное пространство постсоветской России, теория единого библиотечного фонда, вклад советских и российских библиотековедов в конщепџию единого библиотечного фонда страны, государственная культурная политика России. 
Российские библиотеки более двух десятилетий генерируют собственный цифровой контент. Организация Национальной электронной библиотеки (НЭБ) стала актуальным направлением развития отечественного библиотечного дела, тесно соприкасающимся с проблемной областью построения информационного пространства страны. Сравнивая традиционную и виртуальную библиотеку и отмечая их сходные черты (например, упорядочение целенаправленно скомплектованного фонда (коллекций) с помощью навигационно-поисковых средств, свойственное обеим разновидностям библиотек), большинство отечественных специалистов не касались оригинальных аспектов электронной библиотеки, что проявилось в ходе дискуссии об организационных основах НЭБ (2004 г.) [1]. Итогом публичных обсуждений стало концептуальное обновление моделирования НЭБ, в результате которого перспективным был признан подход к формированию распределённого электронного фонда [2].

Таким образом, формирование национального библиотечного репертуара электронных документов определяет основное содержание и условия функционирования одного из сегментов (инфосферы) единого информационного пространства России [3].

Российская государственная библиотека (РГБ) и Российская национальная библиотека (РНБ), учреждая НЭБ, провозгласили её открытость «для партнёрского участия всех библиотек, организаций и учреждений науки, культуры и образования вне зависимости от ведомственного подчинения, расположенных на территории Российской Федерации». За годы реализации программы удалённый доступ к распределённому фонду электронных документов НЭБ открыли РГБ, РНБ, Парламентская библиотека и ГПНТБ России, используя систему виртуальных читальных залов (ВЧЗ) [4]. Однако сервис доступа нуждается в коррекции и развитии, поскольку не везде достигнут необходимый стандарт качества. Самая обширная сеть РГБ доступна пользователям в городах России и зарубежных странах [5].

Новая концепция «Национальной электронной библиотеки Российской Федерации» (с декабря 2014 г.) презентует федеральную государственную информационную систему построения цифрового пространства знаний, используя портал НЭБ - единую точку доступа ко всем ресурсам НЭБ (как открытым, так и защищённым авторским правом). Её программы предусматривают «создание условий для координации усилий органов государственной власти, библиотек разного уровня, библиотек образовательных и научных учреждений, музеев, архивов, государственных и муниципальных организаций в создании единого национального электронного пространства знаний, формировании благоприятной информационной среды; расширение возможностей граждан на доступ в электронном виде к проверенной, надёжной и актуальной информации через сеть “Интернет"» [6, с. 170].

Функционирование портала предусматривает ежегодное включение в НЭБ «не менее 10 процентов, издаваемых в Российской Федерации наименований книг» [6, с. 169]. Доступ к более 250 цифровым коллекциям, созданными центральными библиотеками субъектов Российской Федерации позволит достичь «унифицированного доступа к электронным ресурсам, проводить оценку их достоверности и актуальности, что даёт возможность радикального повышения качества информационного обслуживания» [6, с. 169].

Немаловажной проблемой является сохранность документов и их коллекций в дестабилизирующих условиях стихийного формирования информационного контента сетевого пространства и игнорирования им норм авторского права [3]. Решение проблемы, по крайней мере, в информационном пространстве страны, специалисты связывают с правомочной деятельностью Национальной электронной библиотеки (НЭБ) как гаранта социальной ответственности «перед научным, образовательным и культурно-просветительским сообществом, настоящим и будущими поколениями» $[2,3]$, хранящего и открывающего доступ к накопленному наследию всем категориям пользователей.

Ресурсная база НЭБ, безусловно, информационно насыщенна. Доступ к фондам национальной электронной библиотеки, очевидно, способен приостановить сокращение числа библиотек, находящихся в ведении органов муниципального самоуправления. Делегируя часть властных 
полномочий на муниципальный уровень, государство допускало возможность финансирования библиотечного строительства на местах из средств бюджетов различных уровней. Новая стратегия НЭБ в чём-то корректирует прежнюю стратегию, обеспечивая на государственном уровне ресурсные возможности низовых муниципальных библиотек. Вместе с тем, актуализируется вопрос о целесообразности столь обширной сети библиотек страны, в том числе в её муниципальном сегменте.

Становится очевидным, что открытый доступ к оцифрованным фондам национальных библиотек фактически нивелирует значимость любой другой библиотеки, если всю информационную работу свести именно к доступности фондов.

Осознание необходимости формирования библиотечного пространства нашло своё отражение на страницах «Положения о библиотечном деле в СССР» (1984 г.), потребовавшем создания единого библиотечного фонда [7]. Это решение, принятое на высоком государственном уровне, сообщило, по мнению Ю. Н. Столярова, недостающую юрисдикцию теоретическому тезису о едином библиотечном фонде страны [8, с. 19]. В трактовке Ю. А. Гриханова, легитимность в первую очередь касается цели новой государственной библиотечной политики - сопряжения «разобщённых, дублирующих друг друга библиотек в единую библиотечную систему» [9, с. 21]. Создание единого библиотечного фонда страны рассматривалось Ю. А. Грихановым как центральная задача, решение которой обеспечивало «стратегический путь к интенсификации библиотечного дела» [9, с. 21].

Несколько лет, прошедшие со времени принятия «Положения о библиотечном деле в СССР», позволили специалистам представить уровень теоретической разработки идеи единого фонда страны и межбиблиотечного взаимодействия и оценить его в сравнении со смежными науками и областями практической деятельности, также имеющими документальные фонды. Результаты оценки были представлены в тематическом сборнике трудов Московского государственного института культуры (1988 г.) [10]. Информационная значимость этого выпуска продолжающегося издания состоит не столько в подытоживающем характере представленных в нём публикаций, сколько в том, что на его страницах раскрывается методология подхода, позволяющего понять концепцию единого фонда.

Собственно, речь идёт о работах Ю. Н. Столярова и Ю. А. Гриханова. Оба автора уделили должное внимание терминологическому аспекту, позволив убедиться в преемственности терминов «единый общесоюзный библиотечный фонд»-«единый библиотечный фонд»«территориально распределённый единый библиотечный фонд». Истоки формирования теории единого библиотечного фонда Ю. Н. Столяров связывает с именем библиотекаря Московского университета Ф. Ф. Рейса, предложившего в 1826 г. «рассматривать книжные фонды немногочисленных тогда библиотек как единую систему. Основой единства должны были стать: сводный каталог, координация комплектования и межбиблиотечный абонемент» [8, с. 5]. Отдавая должное академическим библиотекам дореволюционной России, оценившим экономические и организационные преимущества целостности всей совокупности подразделений фонда, Ю. А. Гриханов склонен связывать эволюцию понятия «единый фонд» с практикой развития ведомственных централизованных библиотечных сетей по пути межсетевого взаимодействия. Таким образом, для Ю. А. Гриханова единый библиотечный фонд является понятием отечественного фондоведения периода начала 70-х гг. прошлого века [9].

Для Ю. Н. Столярова обращение к анализу предпосылок создания единого фонда, говоря словами Ю. А. Гриханова, не означает упрощенческой методологии, о чём предупреждал оппонент. Широкая, общегосударственная, межведомственная трактовка многолетней истории концепции единого библиотечного фонда страны, по мнению Ю. Н. Столярова, «характерна < ..> для отечественного фондоведения, которое, $<\ldots>$ в данном отношении занимает передовые позиции в мировом библиотековедении» [8, с. 20]. Подобное расхождение во мнениях о едином библиотечном фонде страны ведущих специалистов кроется в их программных установках исследования единого фонда. Если для Ю. А. Гриханова предметом рассуждений является технологический 
аспект формирования единого общесоюзного библиотечного фонда [9, с. 19], то внимание Ю. Н. Столярова в большей степени уделено административному ресурсу - роли государственной библиотечной политики в формировании единого библиотечного фонда [8, с. 3]

В определённом смысле, рассматривая государственные решения в области библиотечного строительства, Ю.Н. Столяров исследует этапы формирования библиотечного пространства страны, для которого концепция единого библиотечного фонда является технологией существования. Предлагая широкую трактовку истории концепции единого общесоюзного библиотечного фонда на протяжении периода с 1918 по 1984 гг., Ю. Н. Столяров невольно освещает степень внедрения технологии единого фонда в практику отдельных видов библиотек. Например, говоря о формировании концепции единого фонда библиотек страны, он кратко оценивает перспективы системы сводного каталога, предложенной в 1918 г. А. И. Браудо. Однако большее внимание автором уделено роли государства в управлении библиотечным пространством, пульсирующей дискретности в развитии видов библиотек, роли экономической поддержки государством внедрения передовых зарубежных информационных технологий.

По мнению Ю. Н. Столярова, единый фонд необходимо рассматривать на уровне региона и в масштабе страны в контексте внесословной доступности фондов и межбиблиотечного взаимодействия. Единое государственное финансирование для всех библиотек страны создавало базу для практической реализации единого фонда. К 1917 г., считает Ю. Н. Столяров, образцом библиотечного учреждения могла считаться научная или специальная библиотека, обладающая стабильным и достаточным по объёму финансированием, по сравнению с публичными и народными библиотеками. Вместе с тем, и они не были свободны от произвола властей, лакун в комплектовании и несовершенства доступа к фондам, что фактически изымало из обращения значительную часть новых поступлений. Автор не приводит статистических данных о количестве библиотек. Но его замечание о размещении всех видов библиотек «преимущественно в центральной части страны» [8, с. 7], позволяет констатировать ещё одну преграду на пути развития концепции единого фонда - отсутствие библиотек на значительной территории макрорегиона Урала, Сибири и Дальнего Востока. Таким образом, до революции существовал не только непроходимый барьер между фондами научных и массовых библиотек, развивавшихся обособленно и несистематично. Очень значительна была территория, неохваченная библиотечным обслуживанием. Несмотря на это, именно «в дореволюционный период возникла и укрепилась идея <..> о приоритете библиотек общественного назначения в получении произведений печати» $[8$, с. 9].

По мнению Ю. Н. Столярова «многие теоретические и практические предпосылки к образованию единого библиотечного фонда страны были созданы лишь в результате политической и организационной деятельности» [8, с. 20] в масштабах государства. В частности, речь идёт о централизации библиотечного дела, как условии реализации «возможности пользования библиотечным фондом, одновременно рационализируя его использование» [8, с. 20]. Идея о «едином общенародном фонде» вне деления библиотек по ведомственной принадлежности возникла у специалистов - заведующих внешкольными и финансовыми подотделами губернских отделов народного образования - в 1918 г. как один из проектов внедрения централизации библиотечного дела. В проекте С. Д. Масловского общегосударственный единый фонд существовал в региональном масштабе как поместные книжные фонды трёх элементов единой сети (детские и школьные, общеобразовательные, специальные библиотеки) взаимно связанные друг с другом пополнением и обменом [8, с. 10] Управление общегосударственным книжным фондом принадлежит единому для всей Республики центральному органу. «Идея такого “единого фонда" в таком понимании была поддержана 1-й Библиотечной сессией Наркомпроса». По сведениям Ю. Н. Столярова «проект был реализован в Московской и ряде других губерний РСФСР» [8, с. 17]. Добавим, и за Уралом.

На территории бывшего Алтайского округа Томской губернии в г. Барнауле в 1919-1920 гг. существовала централизованная сеть советских библиотек, перераспределившая фонды библиотек, организованных до революции Обществом попечения о начальном образовании. Находясь 
под влиянием общероссийских устремлений физического объединения фондов, городской отдел народного образования предлагал включить в общедоступную сеть фонды крупных личных библиотек.

Как считает Ю. Н. Столяров, первым официальным документом, закрепившим курс библиотечной политики на создание ЕОБФ (единого общесоюзного библиотечного фонда), является декрет «О централизации библиотечного дела в РСФСР» (1920 г.). Стержнем государственного влияния стала передача всех библиотек, не исключая ведомственных и принадлежащих общественным организациям, Наркомпроса.

Суть объединения фондов в систему состояла не в их организационном слиянии, а в установлении средств, благодаря которым они могли бы проводить общую библиотечную политику, тесно взаимодействовать между собой. Функция Наркомпроса мыслилась как < ..> указания <..> равно обязательны для исполнения всеми $<\ldots>$ независимо от их ведомственной принадлежности» $[8$, с. 18$]$.

Ю. Н. Столяров приводит далеко не исчерпывающий перечень документов, который сопровождал изменения в библиотечном пространстве страны. Пожалуй, наиболее информативной частью работы Ю. Н. Столярова являются заявления:

- о сохранившейся автономии деятельности научных и массовых библиотек формированию фондов академических библиотек, особенно с начала 30-х гг., устойчивый полицентризм. В практике массовых библиотек практика полицентрического управления библиотечными фондами дала примеры экспериментов в области организации библиотечной сети;

- о сети государственных массовых библиотек, ставшей в 60-е гг. XX в. самой крупной библиотечной сетью;

- о тенденции к созданию отделов с изолированными комплектованием, обработкой и хранение своих фондов, восходящая к «феодальной» традиции первых крупных библиотек России, долгое время была свойственна многим универсальным научным, а также вузовским библиотекам страны. Иными словами, единого фонда не существовало даже в масштабах одной библиотеки.

В представлении Ю. Н. Столярова единый фонд является продуктом централизованно управляемого информационного собрания, а длительное сосредоточение внимания специалистов на проблеме внутрибиблиотечного структурирования фонда могло быть вызвано отсутствием практики межбиблиотечного сотрудничества [8]. Казалось, что инновации 60-х гг. XX в.библиотечно-территориальные комплексы (БТК) Сибири и органы научно-технической информации, придали «новый аспект идее единого библиотечного фонда». Стоит заметить, что администрирование как стратегический ресурс создания единого информационного пространства, активно внедрялось в практику смежных наук и областей, имеющих документальные фонды. Так существенное опережение формирования единого фонда архивных собраний Ю. Н. Столяров объяснял оперативным и своевременным принятием соответствующего закона и отчасти невнятной основой единства возникающих в библиотечном пространстве новообразований: «создание Единого государственного архивного фонда было объявлено <..> декретом СНК от 1 июня 1918 г. <..> Состав и организация ГАФ СССР были определены «Положением» о нем, утверждённым СНК СССР ещё в 1941 г. < ..> В 1965 г. Министерством культуры СССР утверждено «Положение о Музейном фонде СССР», «Положения» же о библиотечном фонде, как известно, пока не существует, а без него тезис о ЕОБФ не имеет силы закона, а является не более чем декларацией» [8, с. 18].

Стоит признать, что эта точка зрения сблизила позиции ведущих специалистов (Ю. Н. Столярова, Ю. А. Гриханова) концепции единого фонда и заставила признать нивелирование роли библиотек в контексте возросшего культурного уровня народа в системе средств массовой коммуникации, в которой «библиотеки занимают рядовое место» [8, с. 19]. Ю.Н. Столяров, Ю. А. Гриханов оптимистично связывали преимущества ЕОБФ как организованной системы с задачами оптимизации структуры информационного потенциала страны в целях интенсификации его использования и возможностью наиболее полно проводить общегосударственную библиотечную политику $[8,9]$. 
Представляется, что специалисты в конце XX в. расходились во мнениях относительно системообразующего фактора отечественного библиотечного пространства, признавая лидерство за административным руководством и законодательной базой, либо отдавая должное центростремительным тенденциям в развитии библиотечных централизованных систем. Относительно же проявления межбиблиотечного взаимодействия в формате сводного каталога, межбиблиотечного абонемента и централизованной каталогизации разногласий не существовало. Дуализм во взглядах может быть объяснён государственным характером управления всеми областями общественной, экономической и культурной жизни и неуклонным укреплением компетентности специалистов в определении содержания профессиональной деятельности. Именно во второй половине $\mathrm{XX}$ в. были разработаны и внедрены в практику библиотечного сообщества элементы единого языка профессионального сотрудничества, приведшие к осознанию факта единства библиотечного пространства. Речь идёт об отечественных таблицах библиотечно-библиографической классификации и переходе от унификации к стандартизации библиографической записи, преемственности серии стандартов по созданию поискового образа документа.

Эксплуатация Национальной электронной библиотеки, несомненно, внесёт значимые дополнения и обновления в отечественную концепцию библиотечного фонда страны как одного из сегментов национального информационного пространства.

\section{Список литературы}

1. Степанов, В.К. Электронные библиотеки и полнотекстовые базы данных в Интернете // Библиотековедение. - 2004. - № 2. - С. 45-53.

2. История проекта национальной электронной библиотеки // Национальная электронная библиотека : [сайт]. - Москва. - URL: https://rusneb.ru/news/smi/neb-istoriya-ustroystvo-i-novyy-etap-razvitiya/ (дата обращения: 20.01.2014).

3. Национальная электронная библиотека: концепция // Национальная электронная библиотека : [сайт]. - Москва. - URL: http://www.rusneb.ru/conception.htm (дата обращения: 20.01.2014).

4. Основные направления развития Общероссийской информационно-библиотечной компьютерной сети ЛИБНЕТ на 2011-2020 годы: проект // Российская библиотечная ассоциация : [офиц. сайт]. - Москва : [Б. и.], 2011. - 27 с. - URL: rba.ru>content/about/doc/libnet.pdf (дата обращения: 15.02.2020).

5. Виртуальные читальные залы [Электронной библиотеки диссертаций Российской государственной библиотеки] // Электронная библиотека диссертаций Российской государственной библиотеки : [сайт]. Москва, 2003-2020. - URL: http://diss.rsl.ru/?menu=catalog/\&lang=ru (дата обращения: 29.04.2020).

6. Государственный доклад о состоянии культуры в Российской Федерации в 2014 году. - Москва : [Б. и], 2015. - 288 с. : рис., табл.

7. Положение о библиотечном деле в СССР : утв. 3 марта 1984 г.// Справочник библиотекаря / [ К. И. Абрамов, С. Г. Антонова, В. И. Архаров [и др.]; Редкол.: Н. С. Карташов (отв. ред.) и др.]. - Москва : Книга, 1985. - С. 5-14.

8. Столяров, Ю. Н. Единый общесоюзный библиотечный фонд (возникновение и развитие концепции) // Единый библиотечный фонд страны: проблемы формирования : сб. науч. тр. / [редкол. : Л. Н. Герасимова (отв. ред.) и др.]. - Москва : МГИК, 1989. - С. 5-21.

9. Гриханов, Ю. А. Единый библиотечный фонд страны: вопросы технологии формирования и использования // Единый библиотечный фонд страны: проблемы формирования : сб. науч. тр. / [редкол. : Л. Н. Герасимова (отв. ред.) и др.].- Москва : МГИК, 1989. - С. 21-29.

10.Единый библиотечный фонд страны: проблемы формирования : сб. науч. тр. / [редкол. : Л. Н. Герасимова (отв. ред.) и др.]. - Москва : МГИК, 1989. - 146 с.

Anna A. Fomina, Ph. D. In Pedagogics, Associate Professor Altai State Institute of Culture (Barnaul, Russia) terrarium46@gmail.com

\section{A DIGIT AND A TEXT}

Abstract. In 2004, upon an imitative of the biggest Russian libraries, it was founded National E-Library gave an open access to digitally remastered document collections and catalogues of publications stock in Russian libraries. A completeness degree of such public information source that includes 
more than 40 and a half million bibliographic records and around 5 million e-documents for now holds a promise to good perspectives for building all-Russian information space. Idea of the project roots in a theory of united All-Soviet library stock that was elaborated by several outstanding Russian specialists in library document holding theory of the $19^{\text {th }}$ and $20^{\text {th }}$ centuries. The key contribution in the idea made famous Russian specialists in librarianship Yuri Stolyarov and Yuri Grikhanov.

Key words: National E-Library, accessibility of information, information, information space of former-Soviet Russia, a theory of united library stock, contribution of Soviet and Russian specialists in librarianship in a theory of united library stock of Russian state, state cultural policy.

УДК 004.451.55:[165.12-057.875:745/749-037]

DOI: $10.32340 / 2414-9101-2020-3-73-78$

Н. Н. Шаховалов, кандидат педагогических наук, доцент Алтайский государственный институт культуры (Барнаул, Россия) snn_1979@mail.ru

Ю. А. Неприятель Алтайский государственный институт культуры (Барнаул, Россия) neprijatel-art@yandex.ru

\section{РОЛЬ ГИПЕРМЕДИЙНЫХ ТЕХНОЛОГИЙ В ФОРМИРОВАНИИ ПОЗНАВАТЕЛЬНОЙ САМОСТОЯТЕЛЬНОСТИ ОБУЧАЮЩИХСЯ В ПРОЦЕССЕ ДИСТАНЦИОННОГО ОБУЧЕНИЯ ТЕКСТИЛЬНЫМ ВИДАМ ИСКУССТВА}

Аннотация. Рассмотрен феномен возрастающей роли гипермедийных технологий в организации педагогического процесса в современных российских образовательных организациях высшего образования; представлена авторская оценка значения гипермедийных технологий в контексте формирования познавательной самостоятельности обучающихся в дистанционном формате. Авторы указывают на ряд положительных следствий увеличения доли мультимедийных обучающих комплексов в общем массиве дидактического ресурса: существенный прогресс в области качества восприятия информации обучающимися, закрепление образовательной мотивации студентов, персонификация педагогической поддержки, развитие у обучающихся метапредметных навыков и умений, оптимизация временных затрат на обучение. Охарактеризованы инновационные элементы электронного учебно-методического комплекса по войлоковалянию для студентов среднего профессионального и высшего образования, доступного на образовательном портале Алтайского государственного института культуры (Барнаул, Россия).

Ключевые слова: гипермедийные технологии, познавательная самостоятельность обучающиихс, обучающиеся образовательных организачий высшего образования, метапредметные навыки, дистанционное обучение, электронный учебно-методчческий комплекс, войлоковаляние.

В современном образовании важную роль в процессе обучения занимает самостоятельная работа обучающихся. Одновременно значительно возрастает ответственность преподавателей за стимулирование познавательной самостоятельности студентов. Однако педагог 3. Д. Рашидова отмечает, что в процессе обучения в общеобразовательной школе формированию у учащихся умений самостоятельно приобретать знания не уделяется должного внимания. Поэтому свыше 80 \% студентов на первых курсах обучения в высшем учебном заведении не в состоянии самостоятельно отыскать нужную информацию в рекомендуемых учебных и научных изданиях [1, с. 159].

Для нивелирования сложившейся ситуации разрабатываются различные учебнометодические комплексы, способствующие развитию познавательной самостоятельности, боль- 